\title{
Shear strength properties of hybrid (hinoki cypress and Japanese cedar) cross-laminated timber
}

\author{
Seiichiro Ukyo ${ }^{*}$,, Atsushi Miyatake, Kenta Shindo and Yasushi Hiramatsu
}

\begin{abstract}
In this study, the out-of-plane shear strength of hybrid cross-laminated timber (CLT) with outer layers of hinoki (hinoki cypress, Chamaecyparis obtusa) and inner layers of sugi (Japanese cedar, Cryptomeria japonica) is investigated for four different layer configurations. To investigate the influence from rolling shear properties of cross layers on the shear strength of CLT, stress analysis was conducted using the shear analogy method. The nominal shear strength, the maximum shear force divided by the cross-section of CLT, was in the 1.0-2.1 MPa range. Using the shear analogy method, the rolling shear modulus in the cross layer was determined as $72.9 \mathrm{MPa}$, which was comparable with the value obtained for laminae in previous study as well as the value confirmed by strain measurements in the present study. The magnitude of rolling shear stress in the cross layer was 0.9-1.1 times the average shear stress, which was negatively correlated with the nominal shear strength. From the regression line between the nominal shear strength and the magnitude of the shear stress in the cross layer, the mean shear strength of the cross layer was estimated to be $1.33 \mathrm{MPa}$.
\end{abstract}

Keywords: Hybrid cross-laminated timber, Hinoki (hinoki cypress, Chamaecyparis obtusa), Sugi (Japanese cedar, Cryptomeria japonica), Rolling shear, Shear analogy method

\section{Introduction}

Cross-laminated timber (CLT) is a composite panel product with 3-9 layers whose grain directions alternate between $0^{\circ}$ and $90^{\circ}$. Since it has longitudinal grain in two directions, it can be implemented in structural walls and floors. At present, domestic softwoods are used for the production of CLT in Japan. Among the domestic softwood species, sugi (Japanese cedar, Cryptomeria japonica) is the most produced [1]. However, due to its relatively low bending modulus of elasticity, other softwood species are adopted for the outer layer in cases where higher bending stiffness is required. Although mixed-layer configurations with other softwood species are effective for increasing bending stiffness, the shear capacity of the hybrid layer configurations is largely

\footnotetext{
*Correspondence: ukyo@ffpri.affrc.go.jp

Forestry and Forest Products Research Institute, Matsunosato 1, Tsukuba, Ibaraki, Japan
}

influenced by the rolling shear properties of sugi used for inner layers. However, accurately predicting the shear strength of CLT induced by the rolling shear failure is currently difficult for two reasons. The first is due to insufficient data of rolling shear properties for sugi for different laminae dimensions. Numerous studies have shown that the rolling shear modulus of laminae is not material specific, but dependent on the annual ring pattern in the laminae cross-section [2-5]. Test results covering a wide range of laminae dimensions actually used for CLT production are necessary for its prediction. Second, the relation between rolling shear strength of lamina and the shear strength of CLT is not fully described. In practice, exploring this basic relation while confirming the performance of CLT through experiment is necessary.

In this study, to evaluate the shear capacity of a hybrid CLT panel, shear tests under two types of loading conditions were conducted: three-point and asymmetric four-point bending tests. Moreover, effects of layer 
configuration and shear span on the shear strength of CLT panels were investigated. This study aims to examine the relation between rolling shear properties of cross layers and the shear capacity of CLT. The shear analogy method $[6,7]$ was used to investigate the shear stress distribution in the cross-section of the CLT panels.

\section{Materials and methods}

\section{Specimen}

Requirements for manufacturing CLT for use in the Japanese market are described in the Japanese Agricultural Standard (JAS) for CLT [8]. The specimen was fabricated with laminae based on the stress grade specified in JAS. The outer-longitudinal layer of CLT panels comprised laminae fabricated from hinoki (hinoki cypress, Chamaecyparis obtusa), which has a machine stress rated grade of M120A (mean modulus of elasticity: 12.0 GPa; lower limit: $10.0 \mathrm{GPa}$ ). The inner layer comprised laminae fabricated from sugi M30A (mean: $3.0 \mathrm{GPa}$, lower limit: 2.5 $\mathrm{GPa}$ ). The cross-section of laminae was $102 \mathrm{~mm}$ in width and $25 \mathrm{~mm}$ in thickness. Panels were formed by gluing layers of lumber using aqueous vinyl polymer solutionisocyanate (API) wood adhesive. The adhesive was only applied to the faces of laminae and not between edges. The produced CLT panels were classified as Mx120 grade according to the aforementioned standard [8]. Moisture content (MC) was measured with a cut-out sample from the loaded specimen using the oven-dry method. MC was in the $10.4-11.9 \%$ range with a mean of $11.1 \%$. To determine its mechanical properties, laminae were randomly sampled from those prepared for the production of CLT panels. Table 1 shows the modulus of elasticity and density of hinoki and sugi laminae.

As shown in Fig. 1, four types of layer configurations of CLT panels, including 3-layer-3-ply (3L3P) plates, 3-layer-4-ply (3L4P) plates (two inner consecutive layers placed in the same direction), 5-layer-5-ply (5L5P) plates, and 5-layer-7-ply (5L7P) plates (two outer consecutive

Table 1 Mechanical properties of hinoki (hinoki cypress) and sugi (Japanese cedar) laminae

\begin{tabular}{|c|c|c|c|c|}
\hline \multirow{2}{*}{$\begin{array}{l}\text { Statistical } \\
\text { value }\end{array}$} & \multicolumn{2}{|c|}{ Hinoki $(N=70)^{a}$} & \multicolumn{2}{|l|}{ Sugi $(N=66)^{b}$} \\
\hline & $\begin{array}{l}\text { Modulus of } \\
\text { elasticity, Efr } \\
\text { (MPa) }\end{array}$ & $\begin{array}{l}\text { Density, (kg/ } \\
\left.\mathrm{m}^{3}\right)\end{array}$ & $\begin{array}{l}\text { Modulus of } \\
\text { elasticity, Efr } \\
\text { (MPa) }\end{array}$ & $\begin{array}{l}\text { Density, } \\
\left(\mathrm{kg} / \mathrm{m}^{3}\right)\end{array}$ \\
\hline Mean & 12.9 & 477 & 8.57 & 374 \\
\hline SD & 1.5 & 30 & 1.6 & 24 \\
\hline COV & $12 \%$ & $6.3 \%$ & $19 \%$ & $6.4 \%$ \\
\hline
\end{tabular}

a Sample composed of 39 pieces of $0.6-\mathrm{m}$-long laminae and 31 pieces of 2.0-m-long laminae

b Sample composed of 35 pieces of 0.6-m-long laminae and 31 pieces of 2.0-m-long laminae

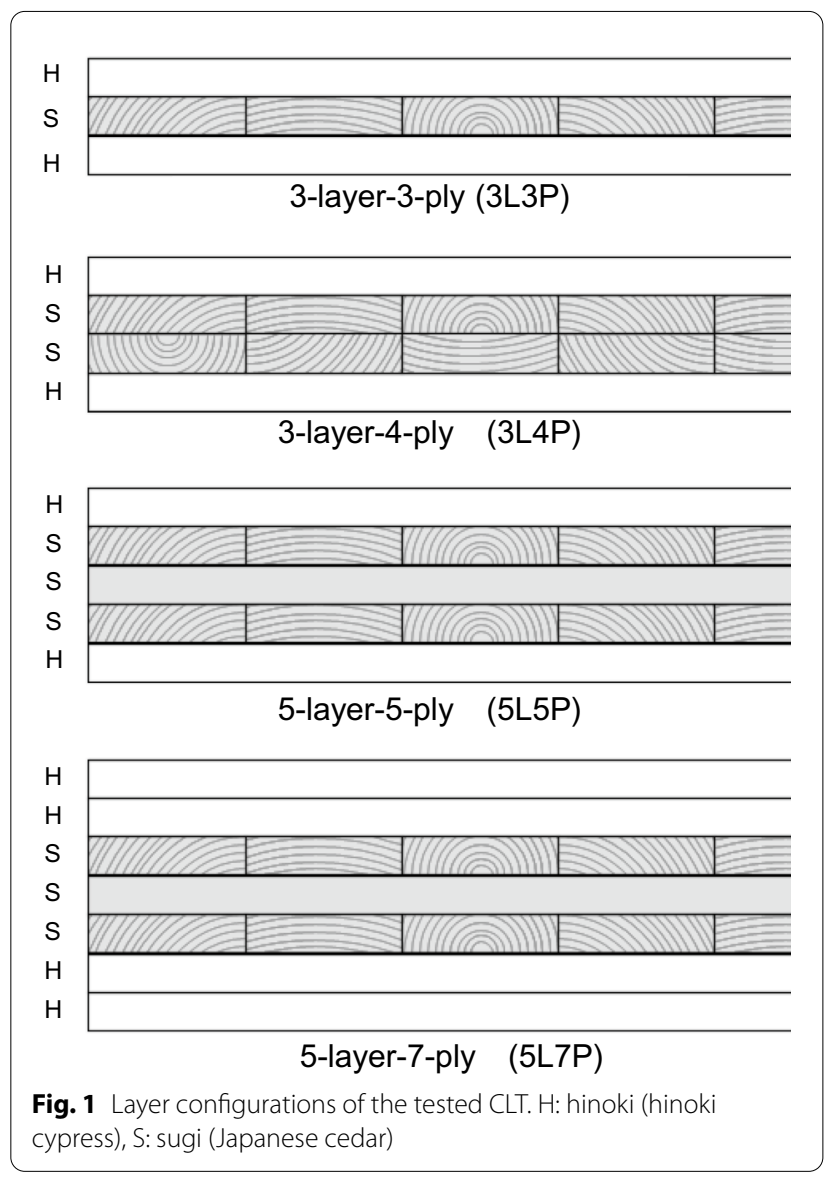

layers placed in the same direction), were tested. Beamlike specimens for the shear tests were cut out from the large CLT panels $\left(6 \times 2 \mathrm{~m}^{2}\right)$. The length of the specimen ranged from 525 to $2365 \mathrm{~mm}$ depending on the depth of the specimen. The width of the specimen was $296 \mathrm{~mm}$.

\section{Shear test configurations}

Loading configurations for the three-point and asymmetric four-point bending tests are shown in Fig. 2. The span-to-depth ratio $(l / d)$ for the three-point bending test was set to $l / d=5$ according to the shear test specification in JAS [8]. To investigate the effect of the spanto-depth ratio on the shear strength, a longer span of $l / d=9$ was added for the 3L3P and 5L5P configurations. To achieve similar stress distributions for the different layer configurations, the widths of the loading plates $\left(w_{\mathrm{lp}}\right)$ were set as equal to the depth of the CLT panels for each layer configuration.

In the asymmetric four-point bending test, the maximum moment can be reduced to half of that in the three-point bending test by setting the distance between the support and loading point as the same as that in the three-point bending test. In this study, however, to compare the shear 


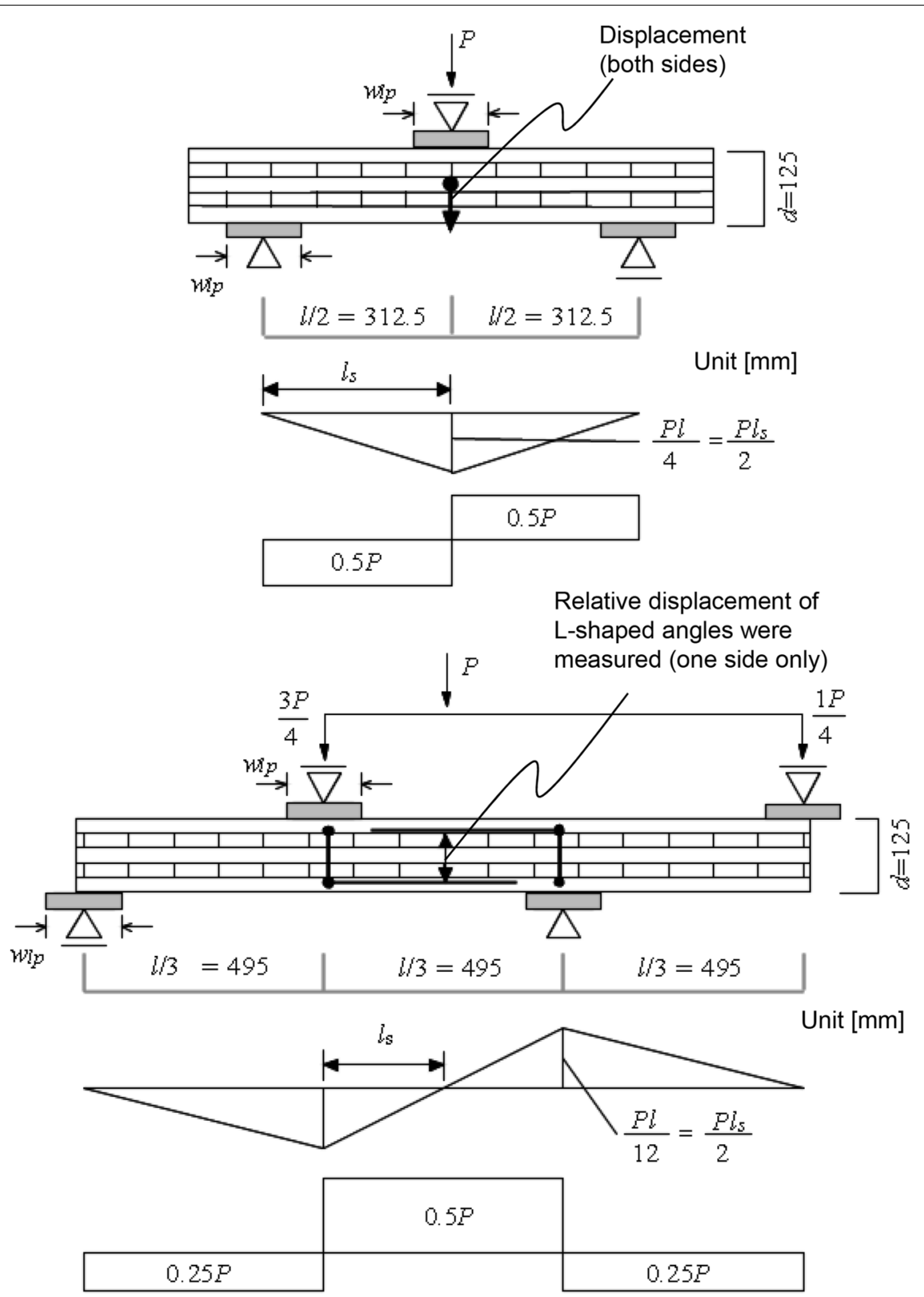

Fig. 2 Loading configurations. Upper: three-point bending test. Bottom: asymmetric four-point bending test. 5L5P, $l_{\mathrm{ef}} / d=1.46$

capacity of two types of loading configurations at equal ratio of bending moment and shear force, i.e., shear spanto-depth ratio $(M /(Q d))$, the spacing of the loads and supports for the asymmetric four-point bending test was set longer than that of the three-point bending test. The shear span-to-depth ratio is calculated as follows:

$$
\frac{M_{\max }}{Q_{\max } \cdot d}=\frac{l_{\mathrm{S}}}{d},
$$

where $l_{\mathrm{s}}$ is the shear span $(\mathrm{mm})$, which is equivalent to the distance between the maximum moment location and the zero moment location, $d$ is the total depth of the CLT panel (mm), $M_{\max }$ is the maximum bending moment $(\mathrm{N} \cdot \mathrm{mm})$, and $Q_{\max }$ is the maximum shear force $(\mathrm{N})$.

Actual shear stress distribution in the shear span is influenced by the loading plates. To achieve the same clear distance, which is not affected by the loading plate, in three-point and asymmetric four-point bending tests, 
the effective shear span-to-depth ratio $l_{\text {ef }} / d$ was calculated with the following equations, for the three-point bending test:

$$
\frac{l_{\mathrm{ef}}}{d}=\frac{\left(l_{\mathrm{s}}-w_{\mathrm{lp}}\right)}{d}
$$

and for asymmetric four-point bending test:

$$
\frac{l_{\mathrm{ef}}}{d}=\frac{\left(l_{\mathrm{s}}-w_{\mathrm{lp}} / 2\right)}{d},
$$

where $w_{\mathrm{lp}}$ is the width of the loading plate $(\mathrm{mm})$. The shear span $l_{\mathrm{s}}$ of the asymmetric four-point bending test was adjusted so that $l_{\mathrm{ef}} / d$ would be as close as possible to that of the three- point bending test.

The loading condition for each layer configuration in the three-point and asymmetric four-point bending tests is shown in Tables 2 and 3, respectively. Displacements transducers were set on both sides of the specimen for the three-point bending test. For the asymmetric fourpoint bending test, a pair of L-shaped target angles were used to obtain the relative displacement. For some specimen, the strain distribution was measured using the digital image correlation method. Prior to testing, speckle patterns were added to the surfaces of the selected specimen. Images were taken with digital cameras (D800, D100, Nikon, Japan) and load value at the time of image acquisition was manually recorded. The distance between the sample and image sensor chip in the camera differed for each sample. The resolution of the image ranged between 0.09 and $0.20 \mathrm{~mm} /$ pixel. The displacement of grid points of an element was calculated using a digital image correlation software VIC-2D (ver.2009, Correlate Solutions, United States of America). The size of an image subset for the calculation of displacement was altered between 21 pixels $\times 21$ pixels and 49 pixels $\times 49$ pixels to obtain the corresponding actual subset size of $4.3 \times 4.3 \mathrm{~mm}^{2}$.

\section{Results and discussion} Nominal shear strength

Figure 3 shows the typical rolling shear failures observed in the two types of loading conditions. Representative nominal shear stress-displacement curves are shown in Fig. 4. The nominal shear stress is calculated by dividing shear force by the CLT cross-section. In the three-point bending test, load decreased immediately after the maximum load had been reached and the final failure mode was shear in the cross layers. In the asymmetric four-point bending test, the load slightly dropped when rolling shear failure initiated in the cross layer. In most cases, further loading resulted in a gradual increase of load and the final failure mode was tensile failure in the outmost layer. In these cases, initial peak load was adopted for the calculation of shear strength. Nominal shear strength was calculated

\begin{tabular}{|c|c|c|c|c|c|c|c|}
\hline Layer configurations & $\begin{array}{l}\text { Specimen } \\
\text { length } \\
L_{\text {sp }}(\mathrm{mm})\end{array}$ & $\begin{array}{l}\text { Shear span } \\
I_{\mathrm{s}}(\mathrm{mm})\end{array}$ & $\begin{array}{l}\text { Width of loading } \\
\text { plate } \\
\text { Wlp }_{\text {lpm }}(\mathrm{mm})\end{array}$ & $\begin{array}{l}\text { Depth of CLT } \\
d(\mathrm{~mm})\end{array}$ & $\begin{array}{l}\text { Shear span-to- } \\
\text { depth ratio } \\
M /(Q d)\end{array}$ & $\begin{array}{l}\text { Effective shear span-to- } \\
\text { depth ratio } \\
l_{\text {ef }} / d\end{array}$ & N \\
\hline \multirow[t]{2}{*}{$3 L 3 P$} & 525 & 187.5 & 70 & 75 & 2.50 & 1.57 & 4 \\
\hline & 825 & 337.5 & 70 & 75 & 4.50 & 3.57 & 4 \\
\hline $3\llcorner 4 \mathrm{P}$ & 700 & 250 & 100 & 100 & 2.50 & 1.50 & 4 \\
\hline \multirow[t]{2}{*}{$5\llcorner 5 P$} & 875 & 312.5 & 130 & 125 & 2.50 & 1.46 & 6 \\
\hline & 1375 & 562.5 & 130 & 125 & 4.50 & 3.46 & 6 \\
\hline $5 L 7 P$ & 1225 & 437.5 & 190 & 175 & 2.50 & 1.41 & 3 \\
\hline
\end{tabular}

Table 2 Loading conditions for three-point bending tests

\begin{tabular}{|c|c|c|c|c|c|c|}
\hline Layer configurations & $\begin{array}{l}\text { Specimen } \\
\text { length } \\
L_{\text {sp }}(\mathrm{mm})\end{array}$ & $\begin{array}{l}\text { Shear span } \\
I_{\mathrm{s}}(\mathrm{mm})\end{array}$ & $\begin{array}{l}\text { Width of loading } \\
\text { plate } \\
W_{\mid p}(\mathrm{~mm})\end{array}$ & $\begin{array}{l}\text { Depth of CLT } \\
d(\mathrm{~mm})\end{array}$ & $\begin{array}{l}\text { Shear span-to- } \\
\text { depth ratio } \\
M /(Q d)\end{array}$ & $\begin{array}{l}\text { Effective shear span-to- } \\
\text { depth ratio } \\
l_{\text {ef }} / d\end{array}$ \\
\hline \multirow[t]{2}{*}{$3 L 3 P$} & 975 & $305 / 2$ & 70 & 75 & 2.03 & 1.57 \\
\hline & 1275 & $520 / 2$ & 70 & 75 & 3.47 & 3.00 \\
\hline $3\llcorner 4 \mathrm{P}$ & 1300 & $400 / 2$ & 100 & 100 & 2.00 & 1.50 \\
\hline \multirow[t]{2}{*}{$5\llcorner 5 P$} & 1500 & $495 / 2$ & 130 & 125 & 1.98 & 1.46 \\
\hline & 2000 & $755 / 2$ & 130 & 125 & 3.02 & 2.50 \\
\hline $5 L 7 P$ & 2365 & $685 / 2$ & 190 & 175 & 1.96 & 1.41 \\
\hline
\end{tabular}

Table 3 Loading conditions for asymmetric four-point bending tests 


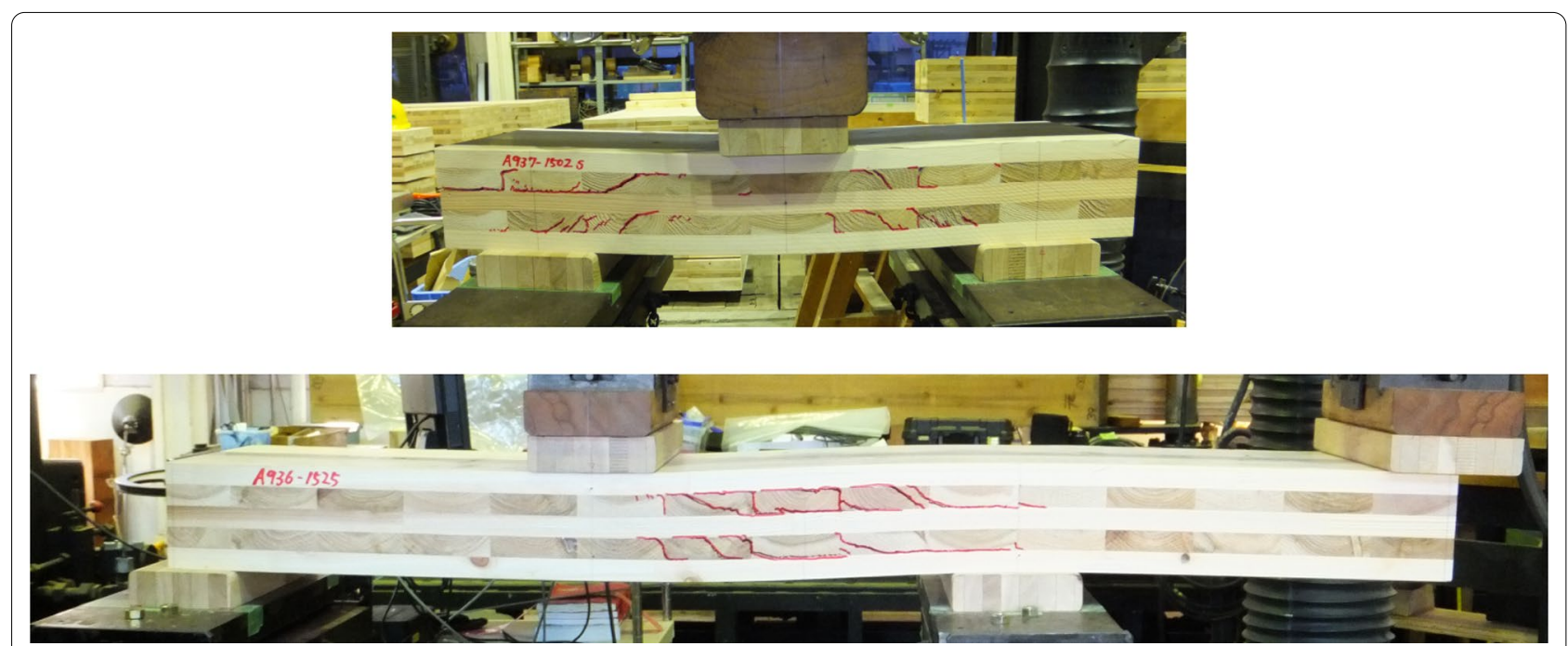

Fig. 3 Typical rolling shear failure observed in the three-point and asymmetric four-point bending tests (5L5P)

by dividing maximum shear force by the net CLT cross-sectional area. In the JAS specification for CLT [8] a factor of 1.5 is multiplied to this value, but omitted in this study.

Summary of the nominal shear strengths obtained from the three-point and asymmetric four-point bending tests is shown in Fig. 5. The figure shows that average nominal shear strength was in the 1.0-2.1 MPa range in the three-point bending tests and 1.01.9 MPa range in the asymmetric four-point bending tests. Comparing the shear strength in the $l_{\mathrm{ef}} / d$ range of 1.4-1.6, the value of 3L3P was significantly higher than those of other layer configurations. Difference in shear strengths among 3L4P, 5L5P, and 5L7P was not evident.

The effect of $l_{\mathrm{ef}} / d$ on shear strength was significant. In the three-point bending tests, the shear strength of larger shear span-to-depth ratios (3.57 and 3.46) was about $60 \%$ lower compared to that of smaller ratios (1.57 and 1.46). In the asymmetric four-point bending tests, a similar decrease in shear strength of $52 \%$ was observed for 3L3P configurations.

\section{Investigation of shear stress distribution in cross-section using shear analogy method}

The shear strength observed in experiments reflected the difference in shear stress distribution along the cross-section. To investigate the shear stress distribution, especially the magnitude of shear stress in cross layers, stress analysis using the shear analogy method $[6,7]$ was conducted.
Implementation of shear analogy method using finite element model

In the shear analogy method, CLT is modeled as two imaginary beams, $\mathrm{A}$ and $\mathrm{B}$. According to the parallel axis theorem, the moment of inertia $I$ of the original crosssection can be divided into two terms [7]:

$$
\begin{aligned}
& I=\int_{A} z^{2} d A=\sum \int_{z_{s i}-}^{z_{s i}+} d_{i / 2}^{d_{i}} z^{2} d A=\sum \frac{b_{i} d_{i}^{3}}{12}+\sum z_{s i}^{2} \cdot A_{i}, \\
& I_{i}^{\mathrm{A}}=\frac{b_{i} d_{i}^{3}}{12}, I_{i}^{\mathrm{B}}=z_{s i}^{2} \cdot A_{i},
\end{aligned}
$$

where $b_{i}$ is the width of the $i$ th layer (in the present study all layers have equal width), $d_{i}$ is the thickness of the $i$ th layer, $z_{s i}$ is the distance from the centroid of the CLT to the centroid of the $i$ th layer, $A_{i}$ is the area of the crosssection of the $i$ th layer, and $I_{i}^{\mathrm{A}}, I_{i}^{\mathrm{B}}$ are the moment of inertia assigned to the $i$ th layer distributed to beams A and B, respectively.

Beam $\mathrm{A}$ is assigned with the first term of the moment of inertia Eq. (2a) and includes the sum of bending stiffness of each individual layer. The shear stiffness of beam $A$ is assumed to be perfectly rigid, i.e., zero shear deformation is assumed. The bending stiffness $B_{\mathrm{A}}$ and shear stiffness $(G A)_{\mathrm{A}}$ of beam $\mathrm{A}$ are expressed as follows:

$$
B_{\mathrm{A}}=\sum\left(E_{i} \cdot I_{i}^{\mathrm{A}}\right)=\sum\left(E_{i} \cdot \frac{b_{i} \cdot d_{i}^{3}}{12}\right),
$$




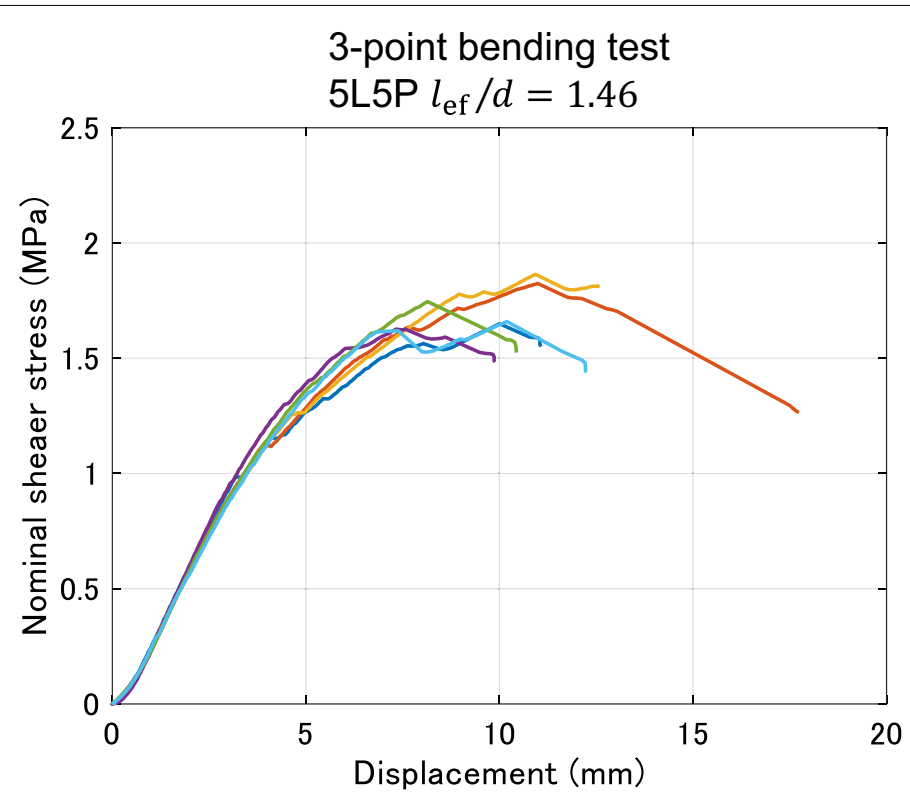

Asymmetric 4-point bending test

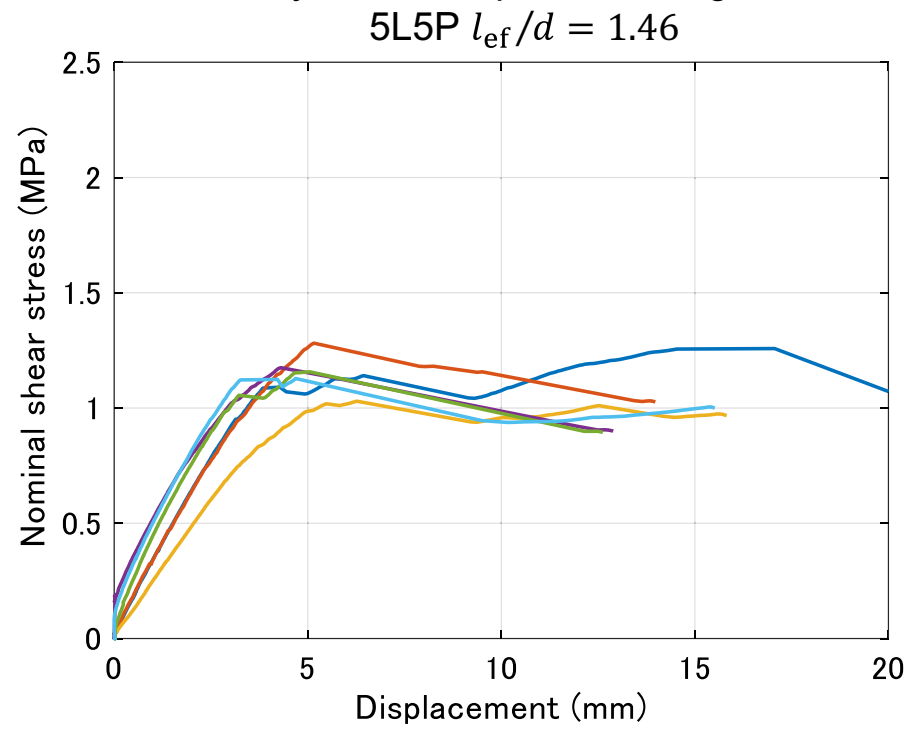

Fig. 4 Relations between nominal shear stress and displacement. Upper: three-point-bending test, $5\left\llcorner 5 \mathrm{P}, \mathrm{l}_{\mathrm{ef}} / d=1.46\right.$. Bottom: asymmetric-four-point-bending test, $5 \mathrm{~L} 5 \mathrm{P}, \mathrm{l}_{\mathrm{ef}} / d=1.46$

$$
(G A)_{\mathrm{A}}=\infty,
$$

where $E_{i}$ is the modulus of elasticity of the $i$ th layer.

In contrast, beam $B$ is assigned with the second term of the moment of inertia (Eq. (2a), often called Steiner's part), and bending stiffness $B_{\mathrm{B}}$ is calculated as follows:

$$
B_{\mathrm{B}}=\sum\left(E_{i} \cdot I_{i}^{\mathrm{B}}\right)=\sum\left(E_{i} \cdot b_{i} \cdot d_{i} \cdot z_{s i}^{2}\right) .
$$

The shear deformation of an entire CLT cross-section of CLT is considered through the shear stiffness of beam B. Shear deformation of CLT is approximated as shown in Fig. 6. The shear stiffness of beam B is calculated as follows:

$$
\frac{1}{(G A)_{\mathrm{B}}}=\frac{1}{a^{2}}\left[\frac{d_{i}}{2 \cdot G_{1} \cdot b_{1}}+\sum_{i=2}^{n-1} \frac{d_{i}}{G_{i} \cdot b_{i}}+\frac{d_{n}}{2 \cdot G_{n} \cdot b_{n}}\right],
$$




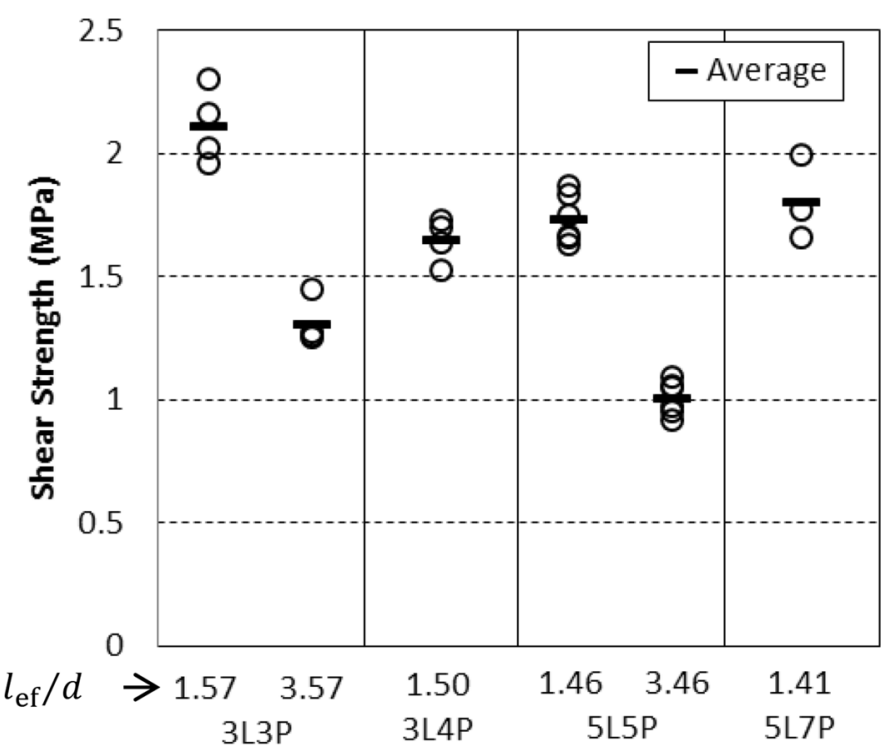

a Three-point bending test

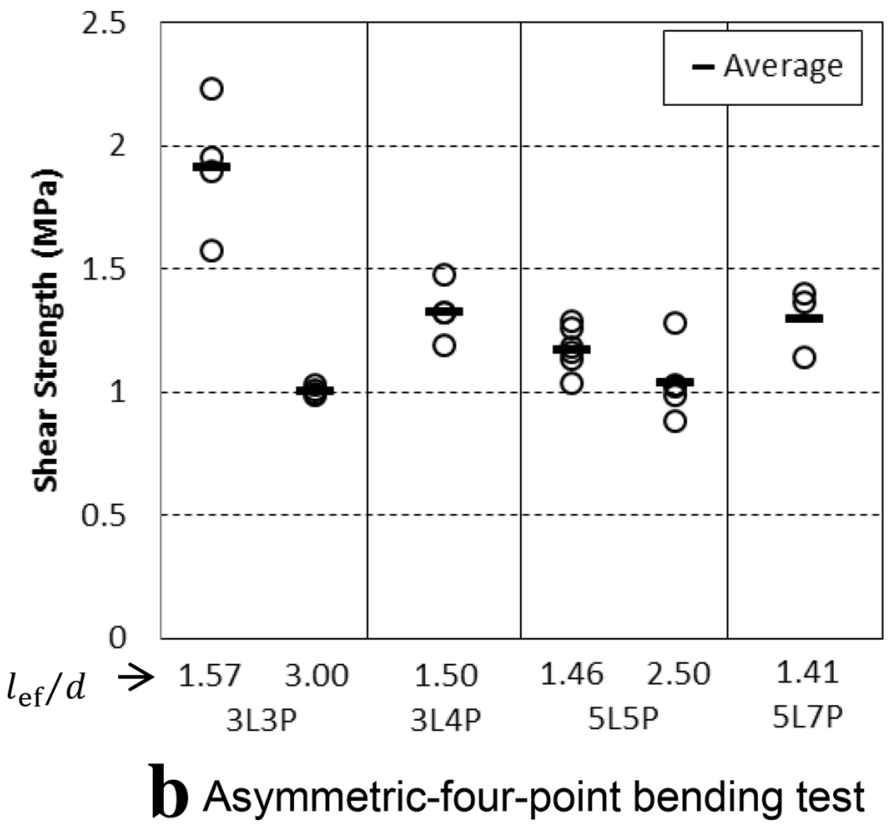

Fig. 5 Nominal shear strength

where $(G A)_{\mathrm{B}}$ is the shear stiffness of beam B, $a$ is the distance between the top and bottom layers, as shown in Fig. 6, and $n$ is the number of layers. For CLT, no mechanical connector was used; hence equivalent shear modulus of the mechanical connections between $i$ th and $(i+1)$ th layers was set to zero.
The bending moments and shear forces of beams A and $\mathrm{B}$, namely $M_{\mathrm{A}}, Q_{\mathrm{A}}, M_{\mathrm{B}}$, and $Q_{\mathrm{B}}$, are calculated under the constraint that the deflection curves of beams A and $\mathrm{B}$ are the same. The deflection coupling of the two beams can be analytically achieved by setting the differential equations of the deflection curves of the two beams to be 


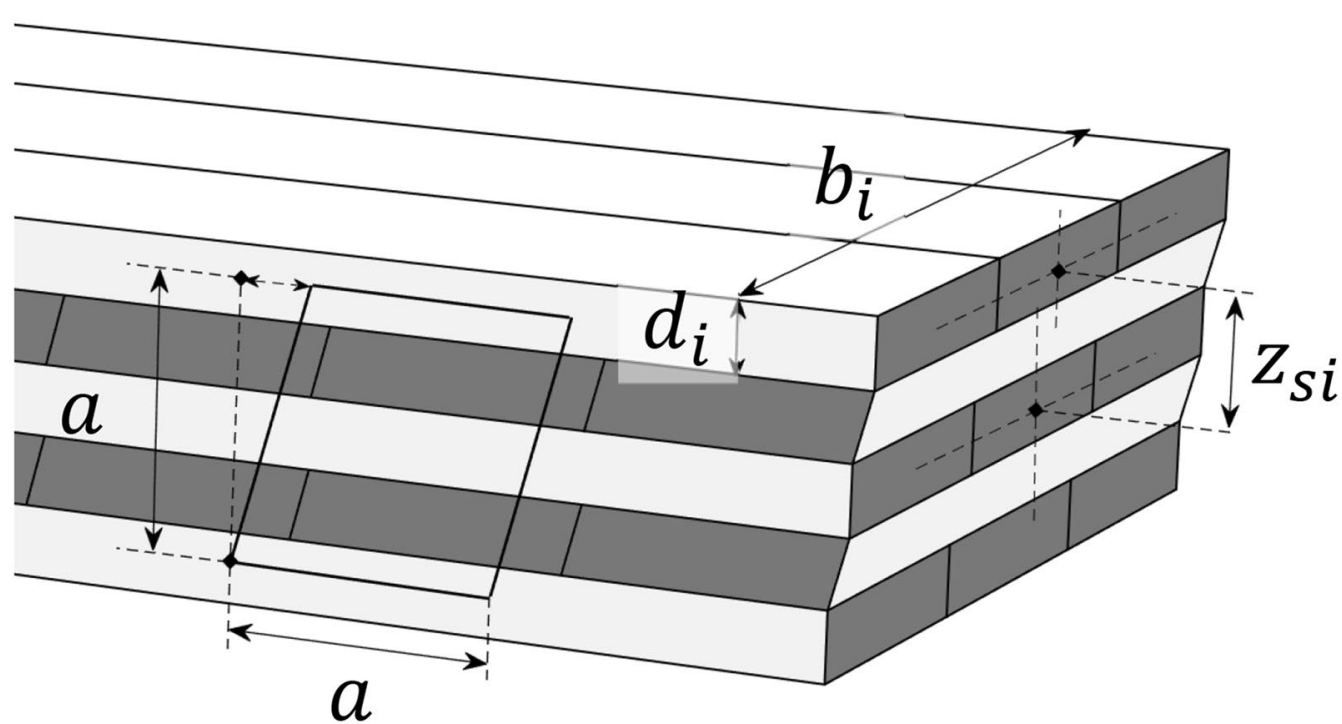

Fig. 6 Dimensions of CLT used for shear analogy method

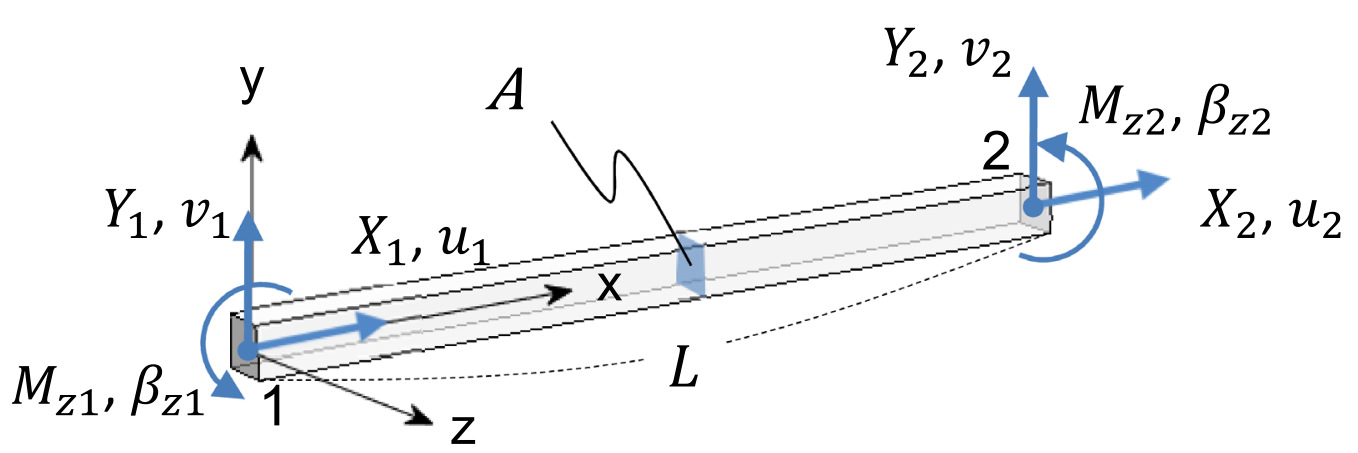

Fig. 7 Two-dimensional beam-rod element used for the finite element method. L: length of the element, $A$ :area of beam, $X_{1}, X_{2}$ : nodal axial force, $Y_{1}$, $Y_{2}$ : nodal shear force, $M_{z 1}, M_{z 2}$ : nodal moment around $z$ axis, $u_{1}, u_{2}, v_{1}, v_{2}$ : nodal displacement, $\beta_{Z 1}, \beta_{z 2}$ : nodal rotation angle around $z$ axis. Subscripts denote the node number

equal, as demonstrated by Scholz [7]. In this study, however, deflection coupling was achieved by modeling the two beams through a finite element analysis model. The same deformation curve can be forced by connecting the two beams with infinitely rigid web members (Figs. 7 and 8a). A two-dimensional stiffness matrix that incorporated a Timoshenko beam [9] and rod element was used for beams $A$ and $B$ and the rigid web member. The stiffness matrix that combines stiffness matrix of rod element $K_{\text {rod }}$ and beam element $K_{\text {beam }}$ is expressed as

$$
\left[\begin{array}{c}
X_{1} \\
X_{2} \\
Y_{1} \\
M_{Z 1} \\
Y_{2} \\
M_{Z 2}
\end{array}\right]=\left[\begin{array}{c:c}
K_{\text {rod }} & 0 \\
\hdashline & \vdots \\
0 & K_{\text {beam }}
\end{array}\right]\left[\begin{array}{c}
u_{1} \\
u_{2} \\
v_{1} \\
\beta_{Z 1} \\
v_{2} \\
\beta_{Z 2}
\end{array}\right]
$$

with

$$
\left[K_{\text {rod }}\right]=\frac{E A}{L}\left[\begin{array}{cc}
1 & -1 \\
-1 & 1
\end{array}\right],
$$




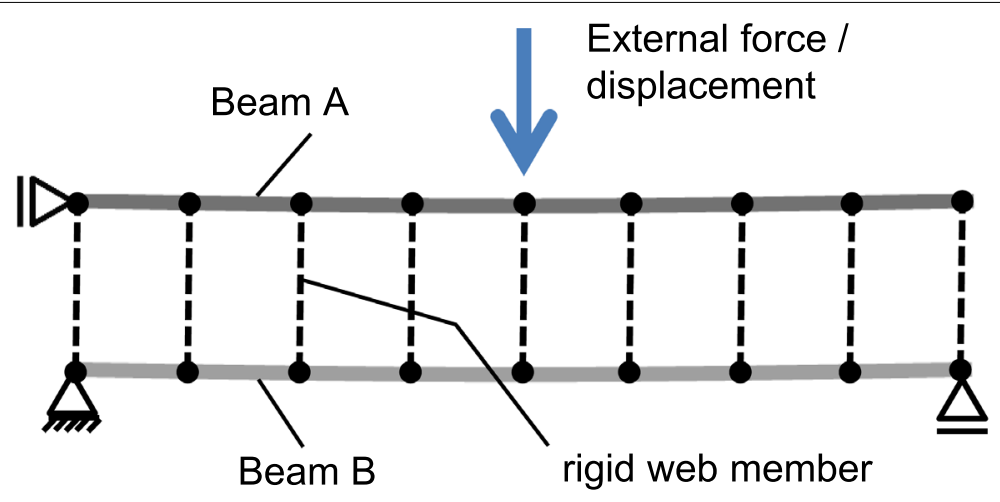

a Analysis model for the shear analogy method
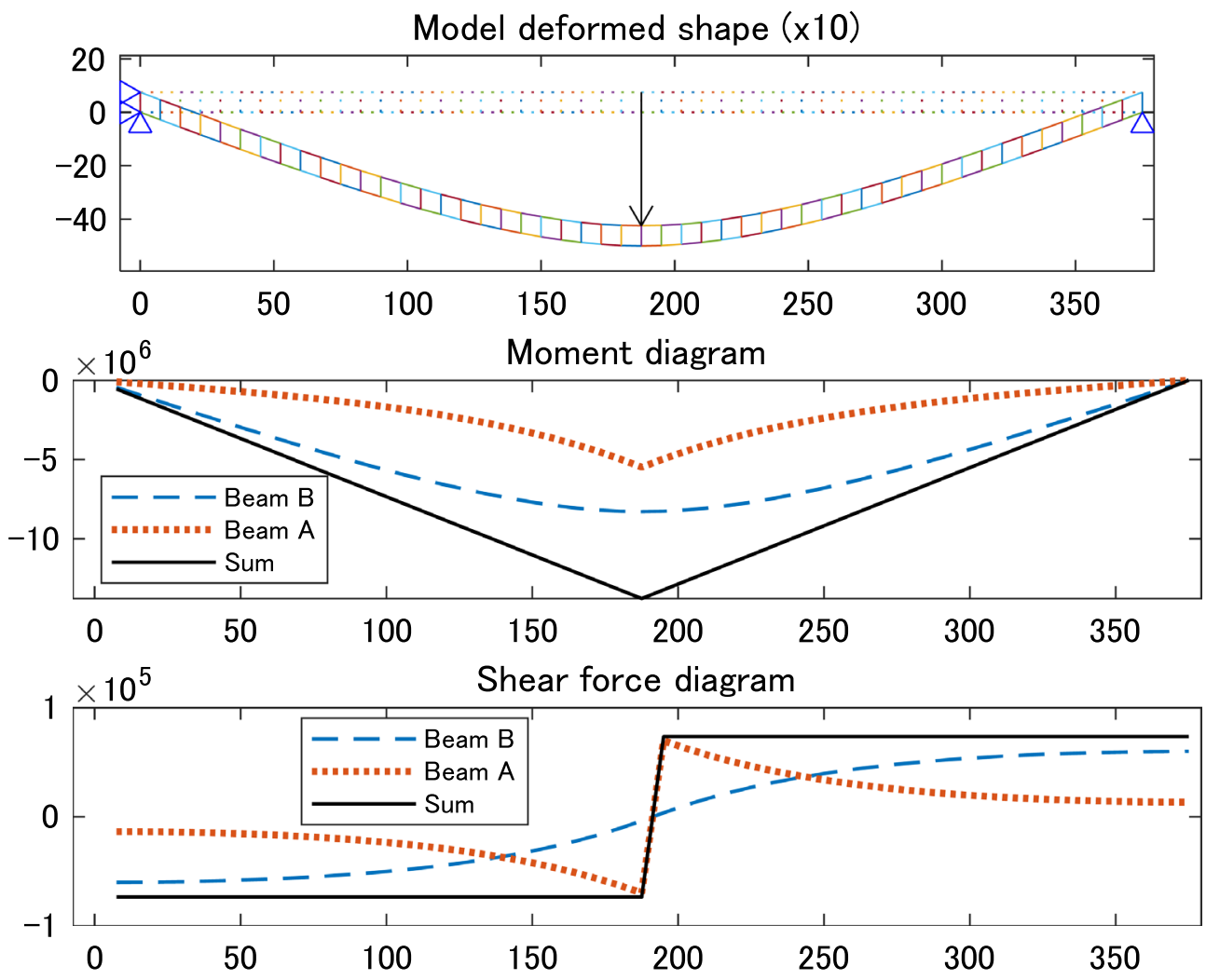

b An example of calculated results for 3L3P specimen

Fig. 8 Analysis model for the shear analogy method and example of results for $3 \mathrm{~L} 3 \mathrm{P}\left(\mathrm{l}_{\mathrm{ef}} / d=1.57\right)$ in three-point bending test

$$
\left[K_{\text {beam }}\right]=\frac{E I_{z}}{L\left(L^{2}+12 S\right)}\left[\begin{array}{cccc}
12 & -6 L & 12 & -6 L \\
& 4 L^{2}+12 S & 6 L & 2 L^{2}-12 S \\
& 12 & 6 L \\
& \text { symmetry } & 4 L^{2}+12 S
\end{array}\right], S=\frac{E I_{Z}}{\kappa(G A)}
$$


Table 4 Material constants used for the shear analogy method

\begin{tabular}{|c|c|c|c|c|c|c|}
\hline \multicolumn{2}{|l|}{$E_{0}(\mathrm{GPa})$} & \multirow{2}{*}{$\begin{array}{l}E_{90}(\mathrm{MPa}) \\
\text { Sugi }\end{array}$} & \multicolumn{2}{|c|}{$G_{0}(\mathrm{MPa})^{\mathrm{a}}$} & \multirow{2}{*}{$\begin{array}{l}\text { G9o(MPa) } \\
\text { Sugi }\end{array}$} & \multirow{2}{*}{$\begin{array}{l}E_{\text {web }}(\mathrm{GPa}) \\
\text { Rigid web }\end{array}$} \\
\hline Hinoki & Sugi & & Hinoki & Sugi & & \\
\hline 12.9 & 8.57 & 0 & 971 & 743 & $72.9^{b}(20-120)^{c}$ & $1 \mathrm{e} 5$ \\
\hline
\end{tabular}

Values from literature $[11,12]$

$E_{\text {Lit }}(\mathrm{GPa})$

Hinoki [11]

Sugi [12]

$G_{\text {Lit }}(\mathrm{MPa})$

13.1

7.35

Hinoki [11]

990

Sugi [12]

637

a The value was adjusted by multiplying a scale factor $E_{0} / E_{\text {Lit }}$ to the parallel-to-grain shear modulus $G_{\text {Lit }}$ from literature [11, 12], where $E_{\text {Lit }}$ and $G_{L \text { Lit }}$ are the modulus of elasticity from the literatures

${ }^{b}$ The estimated value obtained from regression analysis

c Provisional values given for the regression analysis

The nomenclature is described in Fig. 7.

For the element stiffness $\left(E I_{z}\right)$ of beams $\mathrm{A}$ and $\mathrm{B}, B_{\mathrm{A}}$ and $B_{\mathrm{B}}$ were assigned, respectively. Since the shear stiffness of beam $\mathrm{A}\left((G A)_{\mathrm{A}}\right)$ is infinitely large, $\mathrm{S}$ in matrix $K_{\text {beam }}$ was assigned to zero. For beam B, shear stiffness $(G A)_{B}$ calculated through Eq. (5) was used. Since the shear analogy assumes shear stress is equally distributed in the lay-up direction, the shear shape factor $(\kappa)$ for the rectangular cross-section was set to 1.0. The corresponding nodes of beams A and B were connected with infinitely rigid web members. The rigid web member was implemented by replacing the stiffness matrix of the Timoshenko beam $\left(\left[K_{\text {beam }}\right]\right)$ in Eq. (6a) with a zero matrix and by substituting $E_{\text {web }}$ to Eq. (6b). Finite element models (FEMs) were established and analyzed using open-source program code in MATLAB [10].

Figure 8(b) shows an example of the calculated moment and shear force diagram of the 3L3P layer configuration in the three-point bending test. Material constants used for the calculations in Eqs. (2a)-(6c) are listed in Table 4. The moduli of elasticities (MOE, $\left.E_{0}\right)$ in the parallel layer are the average of MOEs measured in laminae sampled from the group prepared for the production of CLT panels. MOE was measured using the longitudinal vibration test. $\mathrm{MOE}$ in the cross layer $\left(E_{90}\right)$ was set to zero. The shear modulus $\left(G_{0}\right)$ of parallel layers for hinoki and sugi were taken from literature values of parallel-to-grain shear modulus adjusted by multiplying a scale factor $E_{0} / E_{\mathrm{Lit}}$, where $E_{\mathrm{Lit}}$ is the modulus of elasticity from literature $[11,12]$. The material constants adopted from the literature are shown in Table 4. Unlike other constants, the shear modulus in the cross layer $\left(G_{90}\right)$ was parametrically determined with regression analysis. For various provisional $G_{90}$ values, the slopes of external force-deflection relations were calculated with the shear analogy method for each layer configuration in the three-point bending test. The unit of the slope was $\mathrm{N} / \mathrm{mm}$. Then, for each provisional $G_{90}$, the sum of the squared difference $(J)$ between the measured and calculated slope was calculated. The reason why only the slope of the three-point bending was used was that the displacement measurement of the asymmetric four-point bending test was affected by the initial alignment of the target angles. The relation between provisional $G_{90}$ and the sum of squared difference $J$ is shown in Fig. 9a. Using fourth order polynomial fitting, the $G_{90}$ value that affords the minimum $J$ was sought. The fourth polynomial was chosen because it afforded the best fit; the coefficient of determination was $R^{2}=1.0$, and no overfitting was observed. As a result of this search, $G_{90}$ was determined to be $72.9 \mathrm{MPa}$. The relation between the measured $\left(K_{\mathrm{EX}}\right)$ and calculated $\left(K_{\mathrm{SA}}\right)$ slopes in this case is shown in Fig. 9(b).

\section{Reverse transformation of moments and shear forces of imaginary beams to normal and shear stress in each layer}

The bending moment and shear force of beams A and $\mathrm{B}$ $\left(M_{\mathrm{A}}, Q_{\mathrm{A}}, M_{\mathrm{B}}\right.$, and $\left.Q_{\mathrm{B}}\right)$ obtained from the FEM calculations were converted to normal and shear stress of each layer with the following equations [7]:

\section{Beam A}

$$
\sigma_{i}^{\mathrm{A}}=\frac{M_{\mathrm{A}}}{B_{\mathrm{A}}} \cdot E_{i} \cdot z_{i} ;-\frac{d_{i}}{2} \leq z_{i} \leq \frac{d_{i}}{2}(i=1,2, \cdots, n),
$$

$$
\tau_{i}^{\mathrm{A}}\left(z_{i}\right)=-\int_{-\frac{d_{i}}{2}}^{z_{i}} \frac{d \sigma_{i}^{\mathrm{A}}\left(z_{i}\right)}{d x} d z=-\int_{-\frac{d_{i}}{2}}^{z_{i}} \frac{d M_{\mathrm{A}}}{d x} \cdot \frac{E_{i}}{B_{\mathrm{A}}} \cdot z_{i} d z=-\frac{Q_{\mathrm{A}}}{B_{\mathrm{A}}} \cdot E_{i} \cdot\left(\frac{z_{i}^{2}}{2}-\frac{d_{i}^{2}}{8}\right) .
$$




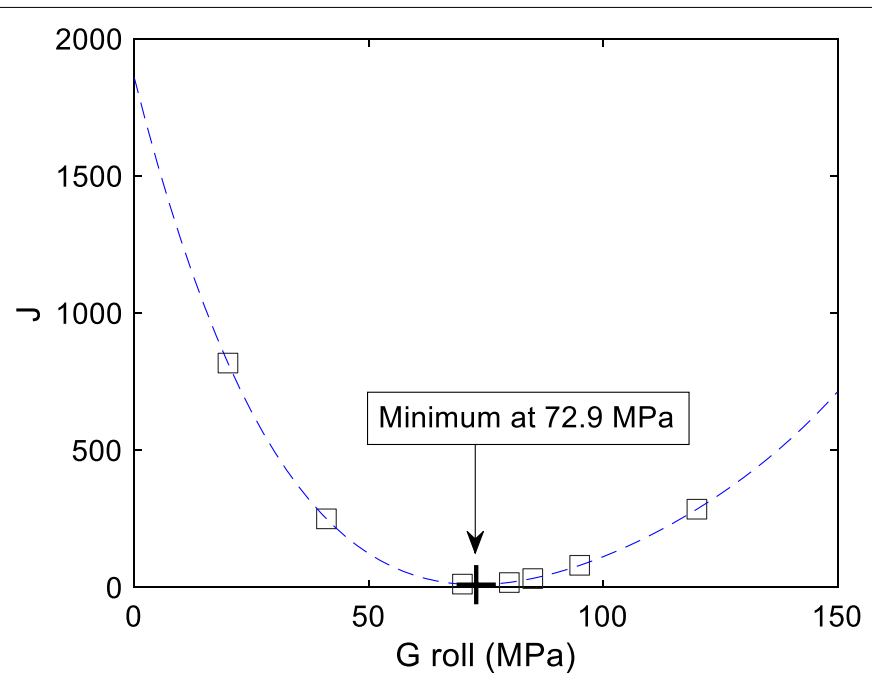

a Relation between provisional rolling shear modulus and sum of squared difference.

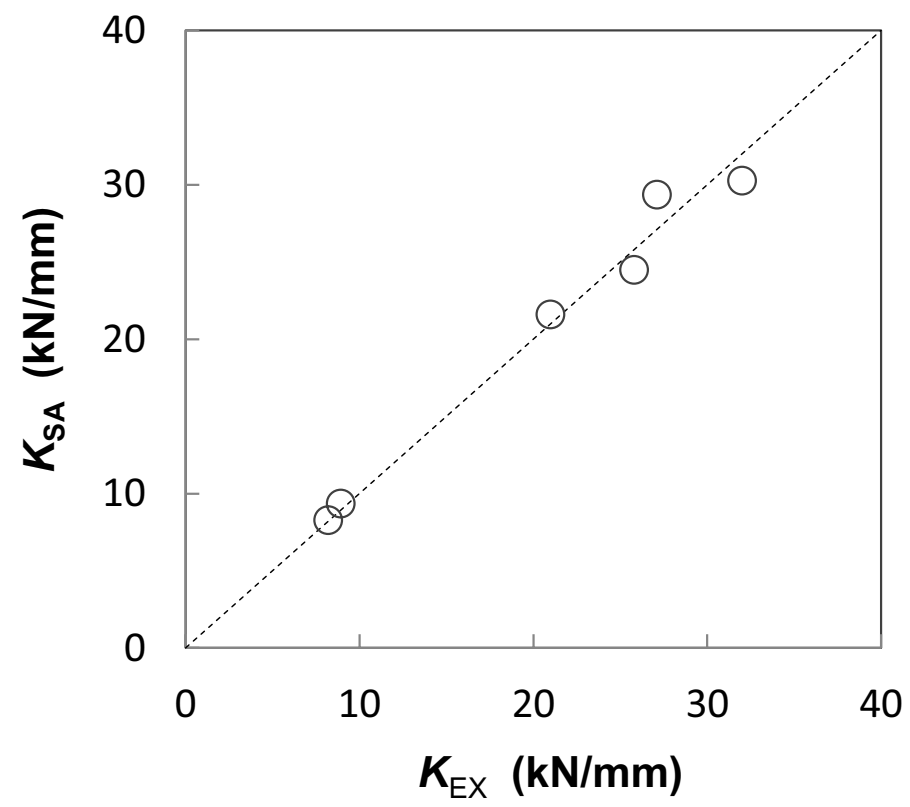

b Relation between measured $\left(K_{\mathrm{EX}}\right)$ and calculated $\left(K_{\mathrm{SA}}\right)$ slopes.

Fig. 9 Determination of shear modulus by comparing the slope of the load deflection curve. J: the sum of squared difference between measured slopes $\left(K_{E X}\right)$ and calculated slopes $\left(K_{S A}\right)$ of external force-deflection curve 


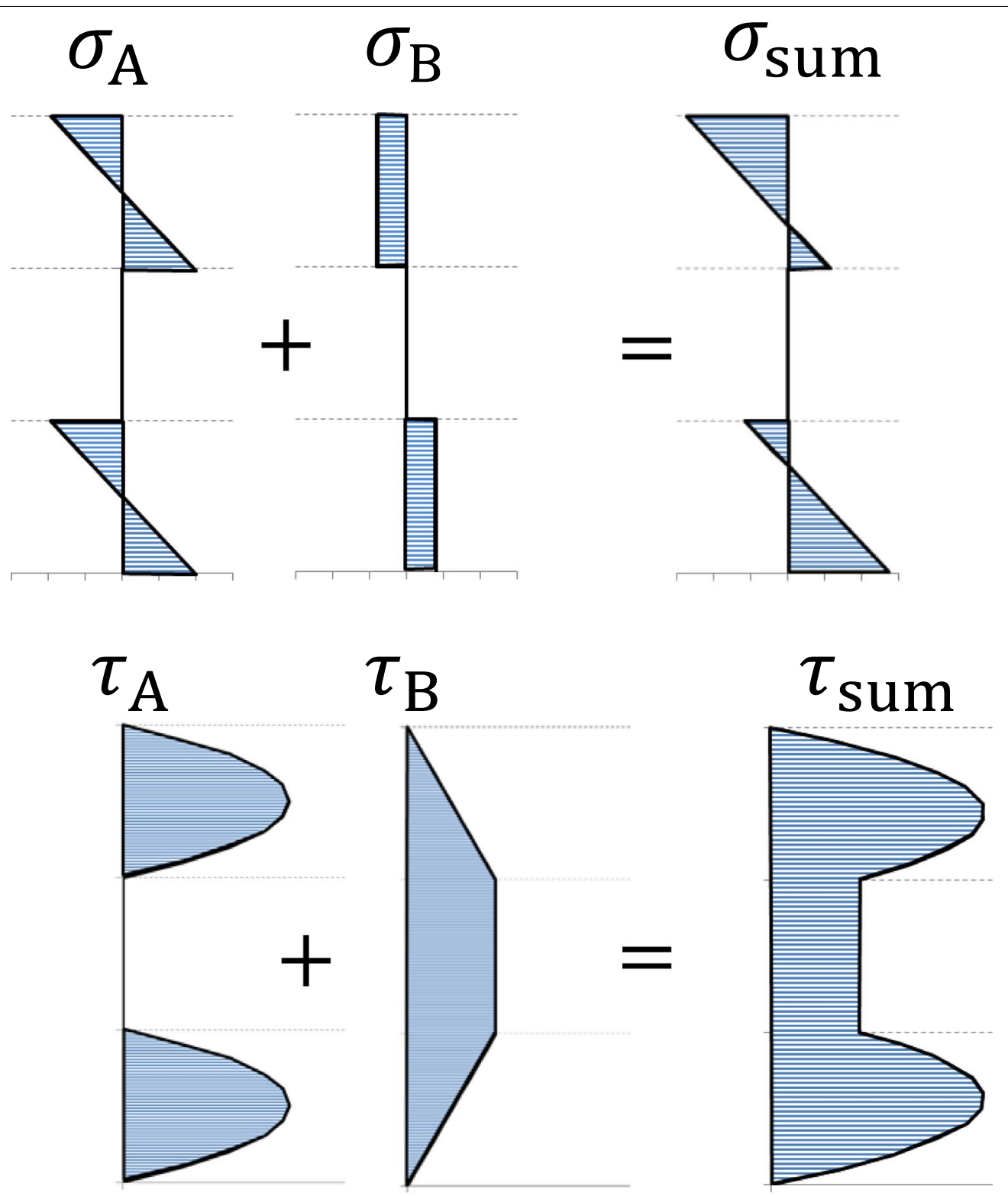

Fig. 10 Axial and shear stress of each layer calculated from the results of the shear analogy method

\section{Beam B}

$$
\sigma_{i}^{\mathrm{B}}\left(z_{s i}\right)=\frac{M_{\mathrm{B}}}{B_{\mathrm{B}}} \cdot E_{i} \cdot z_{s i}
$$

$$
\tau_{i}^{\mathrm{B}}\left(z_{s i}, z_{i}\right)=-\int_{-\frac{d_{i}}{2}}^{z_{i}} \frac{d \sigma_{i}^{\mathrm{B}}\left(z_{s i}\right)}{d x} d z+\tau_{i-1}^{\mathrm{B}}=-\int_{-\frac{d_{i}}{2}}^{z_{i}} \frac{d M_{\mathrm{B}}}{d x} \cdot \frac{E_{i}}{B_{\mathrm{B}}} \cdot z_{s i} d z+\tau_{i-1}^{\mathrm{B}}=-\frac{Q_{\mathrm{B}}}{B_{\mathrm{B}}} \cdot E_{i} \cdot z_{s i} \cdot\left(z_{i}+\frac{d_{i}}{2}\right)+\tau_{i-1}^{\mathrm{B}}, \tau_{0}^{\mathrm{B}}=0
$$



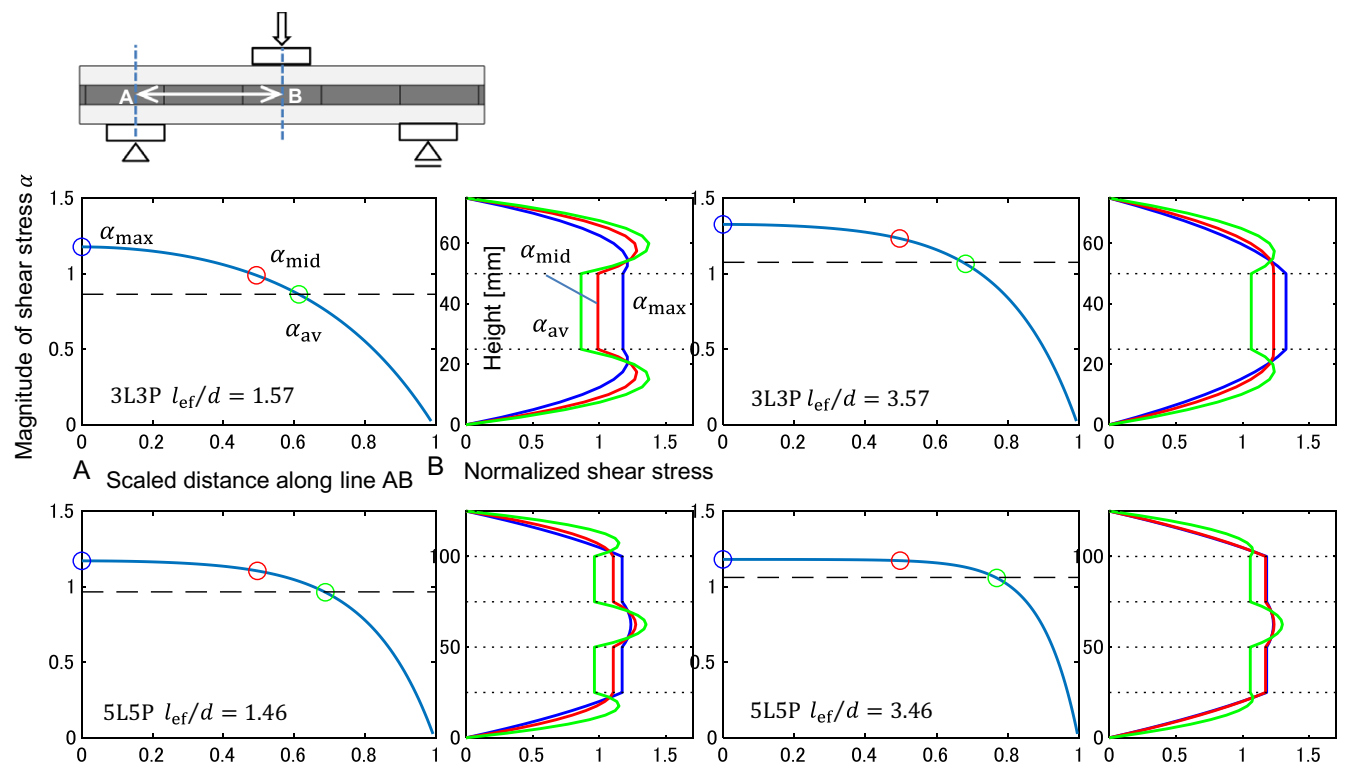

(a) Three-point bending test
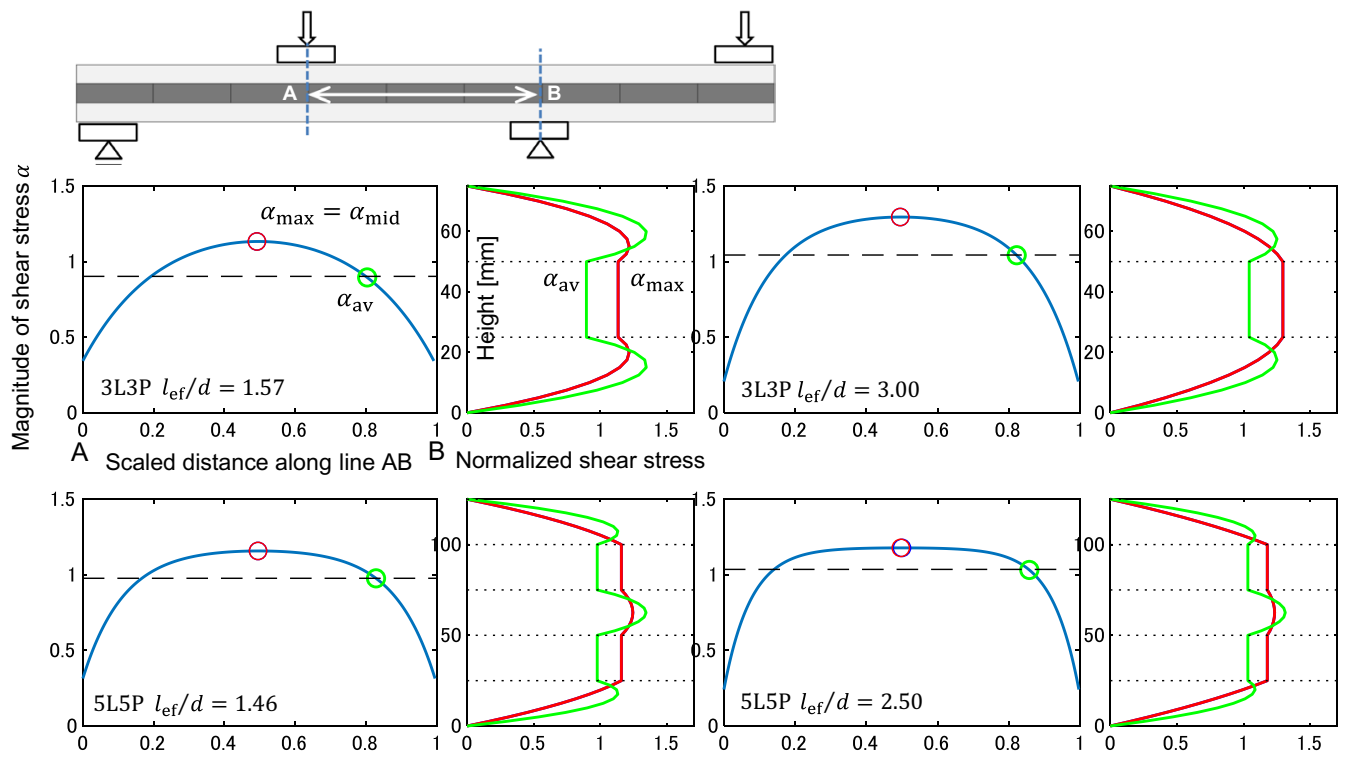

(b) Asymmetric-four-point bending test

Fig. 11 Horizontal distribution of shear stress in the cross layer and cross-sectional shear stress distributions at representative sections

beams $\mathrm{A}$ and $\mathrm{B}$ are summed, respectively, to obtain the normal and shear stress distribution as shown in Fig. 10.

\section{Calculated distribution of rolling shear stress in the cross layer}

For each layer configuration tested, the shear stress distribution was calculated using the shear analogy method. Figure 11a, b shows the distribution of magnitude of rolling shear stress in the cross layer $(\alpha)$ along the shear span direction. The magnitude is normalized by dividing the shear stress value in the cross layer with the average shear stress in that section. In addition, cross-sectional shear stress distributions for the average and maximum shear stress as well as at the middle 

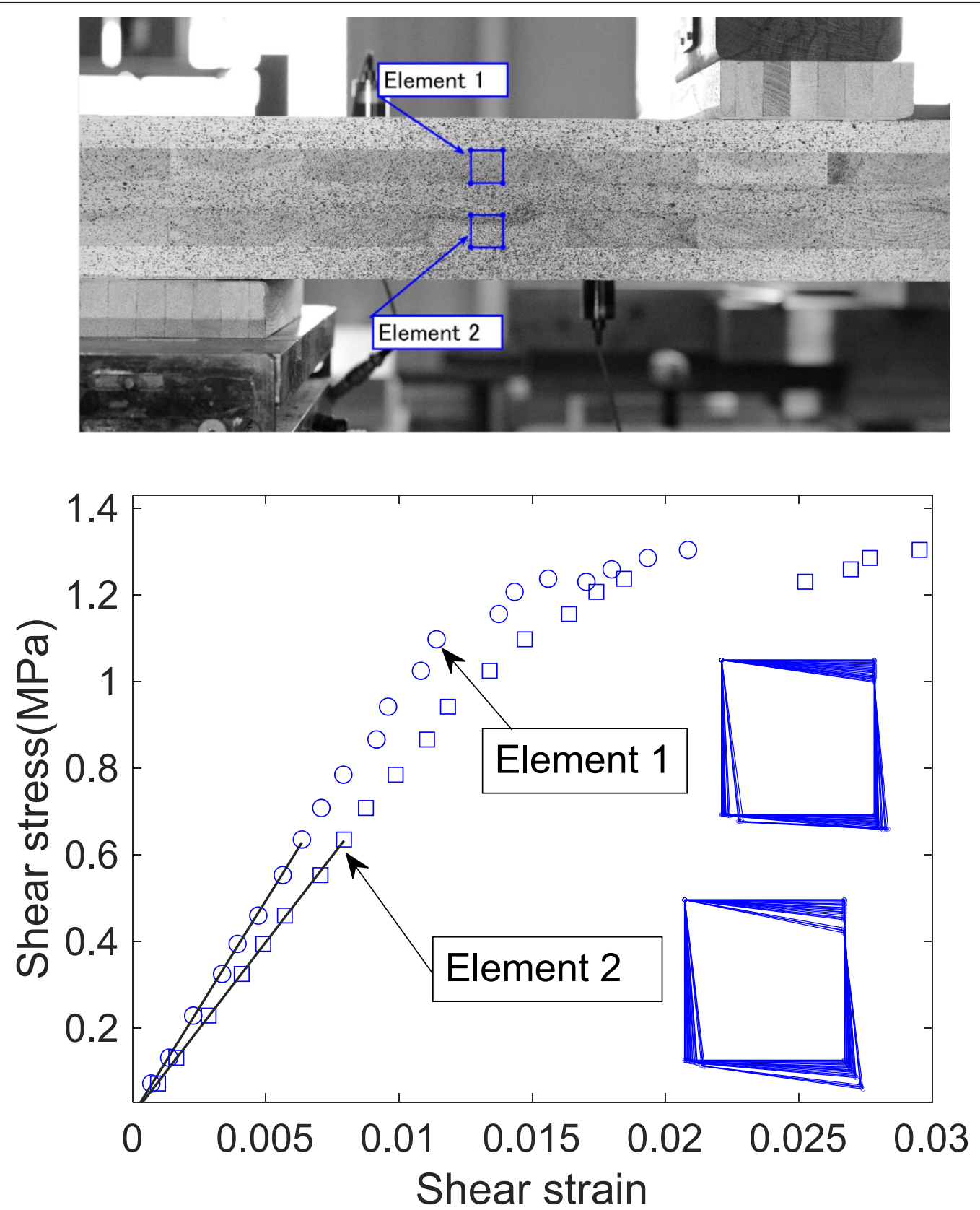

Fig. 12 Sample shear stress-strain curve obtained from the experiment. Shear stress is estimated by multiplying $\alpha_{\text {mid }}$ (see Fig. 11) with the nominal shear stress

of the shear span are shown. In the vicinity of the loading point/support (near point B in Fig. 11), where the sign of shear force changes, the magnitude gradually decreased. The cause of this trend can be explained as follows. As seen in Fig. 8, in the vicinity of the loading point, the shear force taken up by beam B gradually decreases to zero and shifts to beam A. Consequently, the shear stress calculated for beam A will be zero in the cross layer due to the assigned modulus of elasticity $\left(E_{90}=0\right.$, refer to Eq. $\left.7 \mathrm{~b}\right)$. Mestek et al. compared the shear stress distribution calculated with the FEM (modeled with shell element) and the shear analogy method in five-layer CLT in three-point bending tests [13]. The drop of the shear stress in the cross layer in the vicinity of loading point was more pronounced in the shear analogy method compared to the FEM. However, the 
Table 5 Rolling shear modulus estimated from the strain measurement

\begin{tabular}{|c|c|c|c|}
\hline \multicolumn{3}{|l|}{ Specimen } & \multirow{2}{*}{$\begin{array}{l}\text { Rolling shear } \\
\text { modulus G90_ex } \\
\alpha_{\text {mid }}\end{array}$} \\
\hline Layer Config & Loading & $l_{\mathrm{ef}} / d$ & \\
\hline $3\llcorner 3 P$ & Asy. 4-point & 3.00 & 68.3 \\
\hline $3\llcorner 4 \mathrm{P}$ & Asy. 4-point & 1.50 & 65.2 \\
\hline $5 L 5 P$ & Asy. 4-point & 1.46 & 89.4 \\
\hline $5 \mathrm{LP}$ & Asy. 4-point & 2.50 & 65.7 \\
\hline $5 L 7 P$ & Asy. 4-point & 1.41 & 101 \\
\hline $5 L 7 P$ & 3-point & 1.41 & 84.4 \\
\hline Average & & & 79.0 \\
\hline $\mathrm{SD}(\mathrm{COV})$ & & & $14.7(18.7 \%)$ \\
\hline
\end{tabular}

difference of the calculated result decreased (less than 3\%) at a distance equal to the total thickness of CLT away from the loading point. In this study, the characteristic decline of stress was also observed within the distance equal to the total thickness.

\section{Shear modulus in cross layer obtained from strain measurement}

The calculated shear stress levels in the cross layer were used to estimate the rolling shear stress. Figure 12 shows an example of the measured stress-strain relation curves in shear. The shear strain was calculated from the deformations of rectangular elements at the middle of the shear span, as shown in Fig. 12. Corresponding shear stresses in the element was calculated by multiplying the nominal shear stress with the shear stress level factor $\alpha_{\text {mid }}$, which was obtained from the shear analogy method. Shear modulus $G_{90 \_ \text {ex }}$ was obtained from the slope of the stress-strain curve. The shear moduli obtained from the six observations are listed in Table 5 . The mean of the rolling shear $\mathrm{G}_{90 \text { ex }}$ was $79.0 \mathrm{MPa}$ with a coefficient of variation of $19 \%$. In the previous study by Ukyo et al. [5], large variations

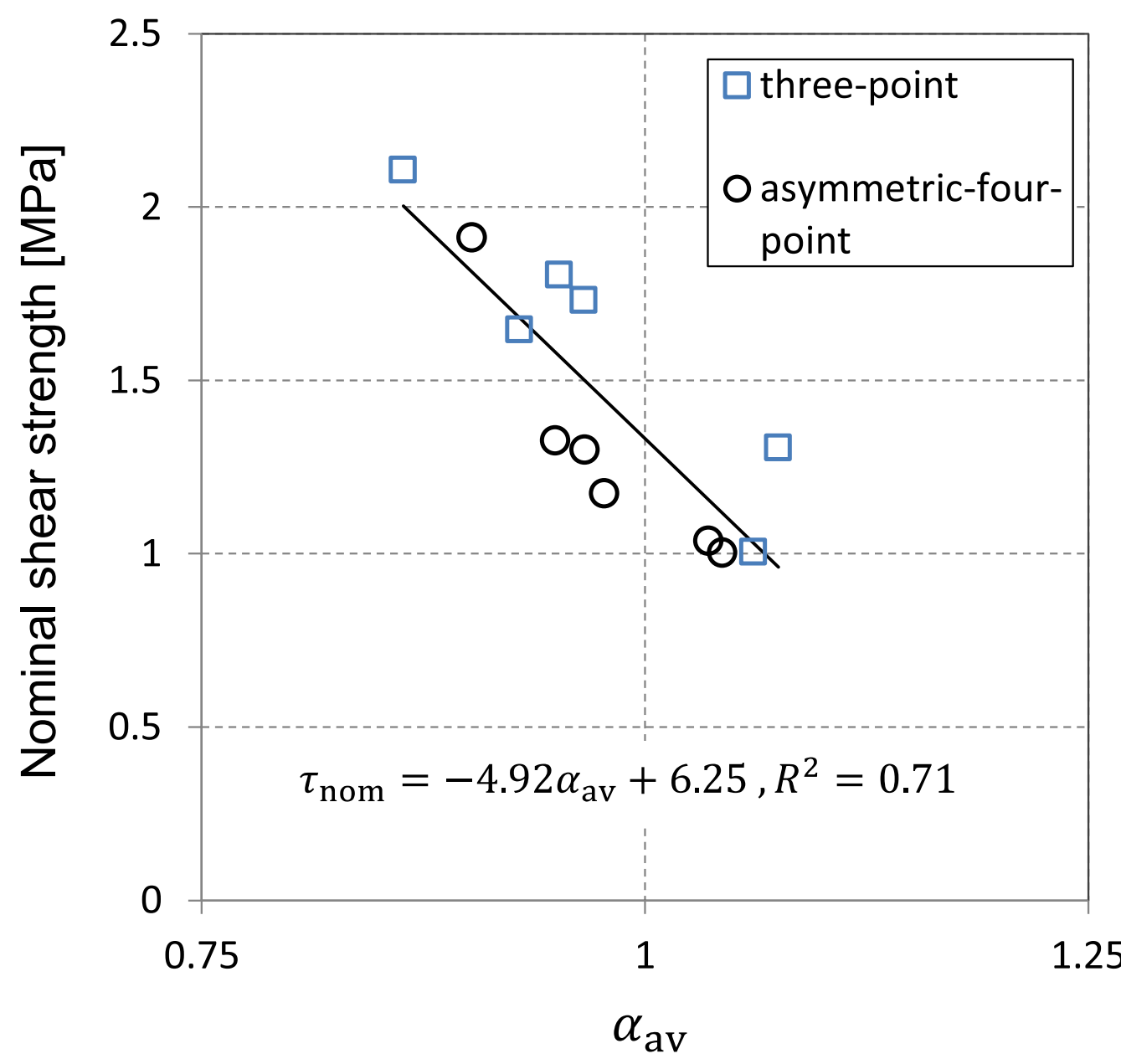

Fig. 13 Relation between nominal shear strength and the magnitude of shear stress in the cross layer $\left(\alpha_{\mathrm{av}}\right)$ 
Table 6 Magnitude of shear stress in cross layer $\left(\alpha_{\mathrm{av}}\right)$

\begin{tabular}{|c|c|c|c|c|c|c|}
\hline \multirow[t]{2}{*}{ Layer config } & \multicolumn{3}{|c|}{ Three-point bending test } & \multicolumn{3}{|c|}{ Asymmetric four-point bending test } \\
\hline & $l_{\mathrm{ef}} / d$ & $\alpha_{\mathrm{av}}$ & $\tau_{\mathrm{nom}}(\mathrm{MPa})$ & $l_{\mathrm{ef}} / d$ & $\alpha_{\mathrm{av}}$ & $\tau_{\mathrm{nom}}(\mathrm{MPa})$ \\
\hline \multirow[t]{2}{*}{$3 L 3 P$} & 1.57 & 0.864 & 2.11 & 1.57 & 0.903 & 1.91 \\
\hline & 3.57 & 1.075 & 1.31 & 3.00 & 1.044 & 1.00 \\
\hline $3\llcorner 4 P$ & 1.50 & 0.929 & 1.65 & 1.50 & 0.949 & 1.33 \\
\hline \multirow[t]{2}{*}{$5\llcorner 5 P$} & 1.46 & 0.966 & 1.73 & 1.46 & 0.977 & 1.17 \\
\hline & 3.46 & 1.061 & 1.01 & 2.50 & 1.036 & 1.04 \\
\hline $5 L 7 P$ & 1.41 & 0.952 & 1.80 & 1.41 & 0.966 & 1.30 \\
\hline
\end{tabular}

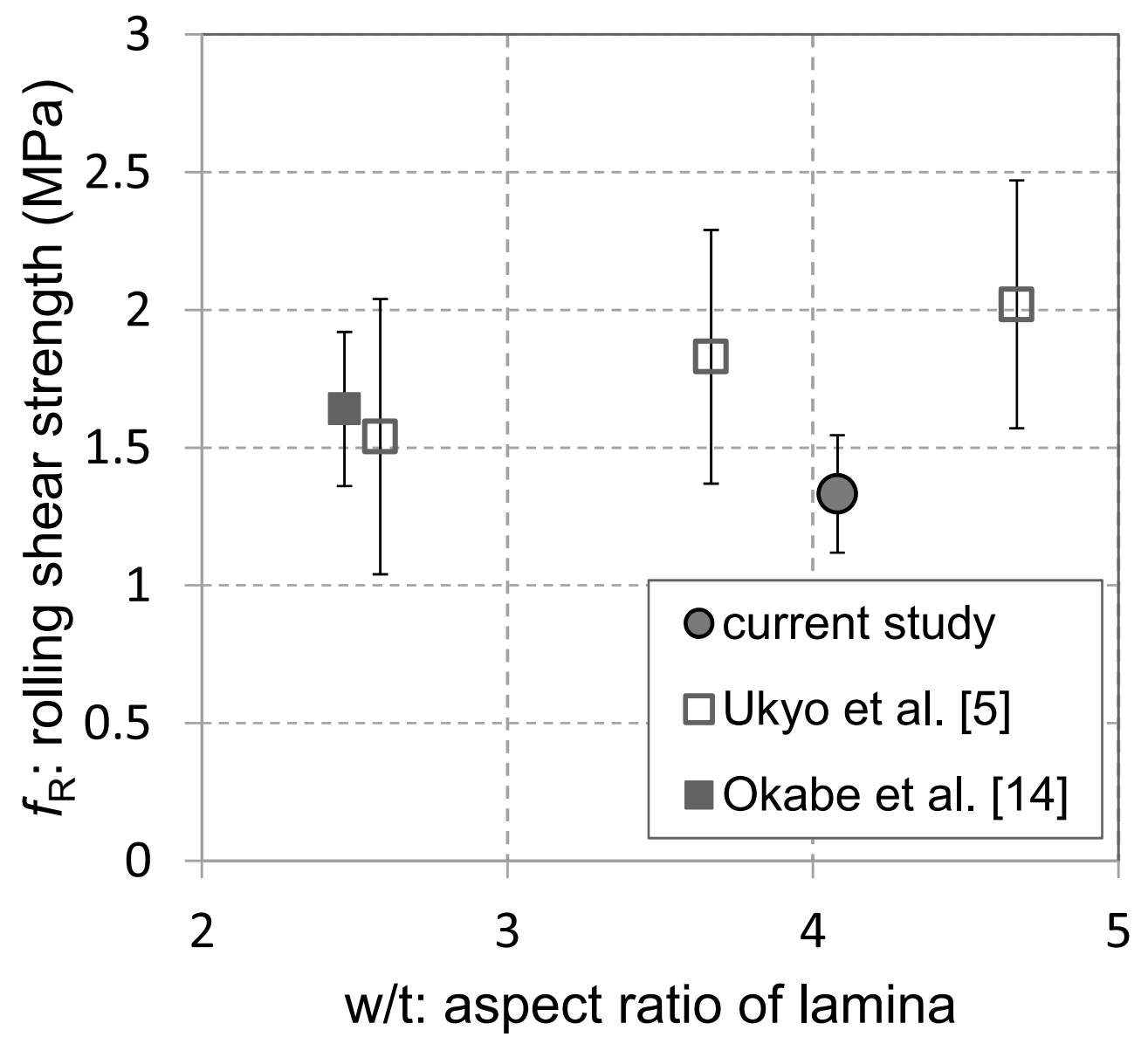

Fig. 14 Comparison of rolling shear strength of sugi (Japanese cedar) obtained in the current study and in previous studies. Error bars for data points of previous studies indicate standard deviation. The error bar of the current study indicates root of mean squared error of the linear regression in Fig. 13

were observed in rolling shear properties of sugi cedar laminae. The mean and coefficient of variation of rolling shear modulus for lamina with $88 \mathrm{~mm}$ width and $24 \mathrm{~mm}$ thickness was $76 \mathrm{MPa}$ and $56 \%$, respectively [5]. Considering the large variance in shear properties of lamina, the measured value was comparable with the value in the previous study [5] as well as the estimated value of $72.9 \mathrm{MPa}$ in the current study. 


\section{Rolling shear strength of cross layer}

As seen in Fig. 11, the shape of the distributions was influenced by layer configuration and shear span. Since the shear capacity of CLT is determined by the rolling shear failure of the cross layer, the maximum rolling shear stress level $\alpha_{\max }$ was considered to have a dominant effect on the nominal shear strength. However, almost no correlation $\left(R^{2}=0.08\right)$ was found between $\alpha_{\max }$ and nominal shear strength. Relations between average rolling shear stress level $\alpha_{\mathrm{av}}$ and nominal shear strength are shown in Fig. 13. The values are also listed in Table 6 . The average stress level $\alpha_{\mathrm{av}}$ was in the range of 0.9-1.1. In both threepoint and asymmetric four-point bending tests a trend was observed where the higher the stress level $\left(\alpha_{\mathrm{av}}\right)$, the lower the nominal shear strength. A linear regression was performed on data points combining the results of both loading methods. From the regression line, the shear strength of the cross layer can be estimated by calculating the value at $\alpha_{\mathrm{av}}=1$, where the shear stress in the cross layer and nominal shear stress coincided. The estimated shear strength of the cross layer was $1.33 \mathrm{MPa}$. Figure 14 shows a comparison of the shear strength of sugi estimated in the current study with that measured by Okabe et al. [14] and Ukyo et al. [5]. The shear strengths are plotted with the aspect ratio of lamina because the effect of aspect ratio on the shear strength was confirmed by Ehrhart et al. [3] and Ukyo et al. [5]. The estimated rolling shear strength was slightly lower compared to the shear strength of nearby aspect ratios. However, note that in the current study, the estimated strength is considered to be a consequence of multiple laminae resisting in parallel, whereas in the previous studies, rolling shear strength was obtained in single lamina tests. Further investigations of the stochastic effect are necessary to clarify the influence of the shear strength distribution of lamina on the shear strength of CLT.

\section{Conclusions}

To evaluate the out-of-plane shear performance of hinoki (hinoki cypress) and sugi (Japanese cedar) hybrid CLT, four different layer configurations were tested in threepoint and asymmetric four-point bending tests. To investigate the influence of the rolling shear properties of cross layers and shear capacity of CLT, the shear analogy method was employed. The nominal shear strength, the maximum force divided by the CLT cross-sectional area, was in the range of 1.0-2.1 MPa in the three-point and 1.0-1.9 $\mathrm{MPa}$ in the asymmetric four-point bending tests. Within the range of effective shear span-to-depth ratio $l_{\text {ef }} / d$ of 1.4-1.6, the strength of 3L3P was significantly higher than that of other layer configurations (3L4P, 5L5P, and 5L7P). The effect of $l_{\mathrm{ef}} / d$ on the nominal shear strength was significant. Compared to smaller $l_{\mathrm{ef}} / d$ ratios, larger ratios showed lower shear strength. Using the shear analogy method, the rolling shear modulus was determined as $72.9 \mathrm{MPa}$, which was in the range comparable with that of previous study as well as the value determined in the strain measurement. The magnitude of shear stress in the cross layer was in the 0.9-1.1 range and was negatively correlated with the nominal shear strength. From the regression line between the nominal shear strength and the magnitude of the shear stress in the cross layer, the mean shear strength of the cross layer was estimated to be $1.33 \mathrm{MPa}$.

\section{Abbreviations \\ CLT: Cross-laminated timber; MC: Moisture content; MOE: Modulus of elastic- ity; FEM: Finite element method; SD: Standard deviation; COV: Coefficient of variation.}

\section{Acknowledgements}

This study is a part of the project on "Technology development for circulatory food production systems responsive to climate change" supported by the Ministry of Agriculture, Forestry, and Fisheries, Japan.

\section{Authors' contributions}

SU performed testing and numerical analysis and was a major contributor in writing the manuscript. MA planned the shear test configurations and contributed to the analysis and interpretation of the data. SK contributed to the improvement of the test set-up. YH contributed to writing the manuscript especially the materials and method part. All authors read and approved the final manuscript.

\section{Funding}

This study is a part of the project on "Technology development for circulatory food production systems responsive to climate change" supported by the Ministry of Agriculture, Forestry, and Fisheries, Japan.

\section{Availability of data and materials}

The datasets used and analyzed in the current study are available from the corresponding author on reasonable request.

\section{Declarations}

\section{Competing interests}

The authors declare that they have no competing interests.

Received: 2 August 2020 Accepted: 25 February 2021

Published online: 10 March 2021

\section{References}

1. Forestry Agency Ministry of Agriculture, Forestry and Fisheries Japan (2019), Annual Report on Forest and Forestry in Japan Fiscal Year 2018 (summary) https://www.maff.go.jp/e/data/publish/attach/pdf/index-176. pdf. Accessed 18 February 2021.

2. Aicher S, Dill-Langer G (2000) Basic considerations to rolling shear modulus in wooden boards. Otto Graf J 11:157-165

3. Ehrhart T, Brandner R, Shickhofer G, Frangi A (2015) Rolling shear properties of some European timber species with focus on cross laminated timber (CLT): Test configuration and parameter study. In: Conference paper of International Network on Timber Engineering Research (INTER), Volume: 2nd Meeting, Sibenik, Croatia, 24-27 August 2015

4. Aicher S, Chirstian Z, Hirsch M (2016) Rolling shear modulus and strength of beech wood laminations. Holzforschung 70(8):773-781

5. Ukyo S, Shindo K, Miyatake A (2019) Evaluation of rolling shear modulus and strength of Japanese cedar cross-laminated timber (CLT) laminae. J Wood Sci 65:31. https://doi.org/10.1186/s10086-019-1810-8 
6. Kreuzinger H (1999) Platten, Scheiben und Schalen. Ein Berechnungsmodell für gängige Statikprogramme (Plates and shells. A calculation model for common structural analysis programs). Bauen mit Holz 1:34-39

7. Scholz A (2004) Ein Beitrag zur Berechnung von Flächentragwerken aus Holz (A contribution to the calculation of plate structures made of wood). Dissertation. Technischen Universität München

8. JAS 3079 (2019) Cross Laminated Timber. . Ministry of Agriculture, Forestry and Fisheries Japan

9. Davis R, Henshell RD, Warburton GB (1972) A Timoshenko beam element. J Sound Vib 22(4):475-487

10. Komatsu K (2013) Kikai Kouzou Dansei Rikigaku (Theory of Elasticity in Mechanical Structure, in Japanese). Morikita Publishing, Tokyo, https:// www.morikita.co.jp/books/book/2676. Accessed 10 May 2019

11. K, Nakato, (ed) (1985) Mokuzai Kougaku (Wood engineering, in Japanese). Yokendo, Tokyo, p 142
12. Forestry and Forest Products Research Institute (2004) Mokuzai Kogyou Handbook (in Japanese). Maruzen, Tokyo, p 135

13. Mestek P, Kreuzinger H, Winter S (2008) Design of Cross Laminated Timber (CLT). World conference on timber engineering WCTE2008, Miyazaki, 2-5 June 2008, CD-ROM.

14. Okabe M, Yasumura M, Kobayashi K (2014) Prediction of internal shear capacity of Sugi CLT panels (in Japanese). Mokuzai Gakkaishi 60(3):169-176

\section{Publisher's Note}

Springer Nature remains neutral with regard to jurisdictional claims in published maps and institutional affiliations.

\section{Submit your manuscript to a SpringerOpen ${ }^{\odot}$ journal and benefit from:}

- Convenient online submission

- Rigorous peer review

- Open access: articles freely available online

- High visibility within the field

- Retaining the copyright to your article

Submit your next manuscript at $>$ springeropen.com 